\title{
On-line Sample Preparation System Using Column-Switching HPLC for the Structure Elucidation of Compounds in Mixtures by NMR
}

\author{
Yumi YoKoYama, ${ }^{\dagger}$ Naoya KISHI, Masayuki TanAKA, and Naoki AsaKaWA \\ Analytical Research Laboratories, Eisai Co., Ltd., 5-1-3, Tokodai, Tsukuba, Ibaraki 300-2635, Japan
}

\begin{abstract}
A new on-line sample preparation system using column-switching HPLC was developed for the structure elucidation of compounds in mixtures by NMR. This system consists of three HPLC sections, separating the compounds of interest (LC-1), trapping the separated compounds on a trapping column using $\mathrm{H}_{2} \mathrm{O}$ and then replacing $\mathrm{H}_{2} \mathrm{O}$ with $\mathrm{D}_{2} \mathrm{O}$ (LC-2), and eluting the compounds from the trapping column using a deuterated solvent for an NMR measurement (LC-3). The system allows easy separation of a trace amount of the compounds from a mixture, desalting and concentration of the separated compounds, and the use of a deuterated solvent, such as $\mathrm{CD}_{3} \mathrm{OD}$, for an NMR measurement. It was successfully applied to the structure elucidation of $( \pm)$-propranolol hydrochloride and a mixture of vitamin $\mathrm{E}$ derivatives as models. This new tool should be of considerable value in various fields for rapid sample preparation for NMR measurements.
\end{abstract}

(Received June 29, 2000; Accepted August 14, 2000)

\section{Introduction}

Nuclear magnetic resonance (NMR) spectroscopy, a very powerful spectroscopic technique, is universally recognized as being complementary to mass spectrometry (MS) for the elucidation of molecular structures, and provides detailed structural and stereochemical information. Conventionally, the use of NMR for the structure elucidation of compounds in mixtures follows chromatographic separation and isolation. However, this traditional off-line approach is often tedious, time-consuming and inefficient. In addition, it is not applicable to compounds that might be degraded during sample preparation. There is, therefore, a need to develop a practical sample preparation method for the rapid structure elucidation of compounds in mixtures.

Recently, the combination of HPLC and NMR spectroscopy (LC-NMR) has become a focus of attention in studies on the structure elucidation of compounds in mixtures, ${ }^{1-3}$ because LCNMR can eliminate the need for isolation prior to an NMR measurement, and the NMR sensitivity and solvent suppression efficiency can be greatly improved., ${ }^{4,5}$ LC-NMR is now a well accepted analytical technique and a number of applications have been reported, e.g., for the analysis of bulk drug impurities, ${ }^{6}$ in vitro and in vivo metabolites,,${ }^{7,8}$ crude plant extracts,, 910 and library mixtures from combinatorial synthesis. ${ }^{11,12}$ The LCNMR method, however, still has several problems. For example, the strong background signals of protons in the mobile phase constituents affect the quality of the NMR spectrum. Although suppression methods to minimize interfering solvent signals are usually used, when the signals of the analyte are very close to the solvent signals, the signals of the analyte may also

To whom correspondence should be addressed.

E-mail: y2-yokoyama@hhc.eisai.co.jp be suppressed in that region. The best way to obtain a highquality NMR spectrum is to use NMR-grade solvents with minimal interfering proton signals in all steps, but these are expensive. Also, in many cases, to maximize the level of the analyte in the LC-NMR flow cell, the HPLC conditions require individual optimization for the separation of the compounds of interest, because the quality of the NMR spectrum depends on the amount of the analyte in the flow cell. Moreover, in order to extend the usefulness of LC-NMR in various fields, it is desirable to exploit various preparative modes to separate compounds in mixtures.

In order to solve the above-mentioned problems, we focused our attention on the column-switching technique. We have established a new on-line sample preparation system consisting of three HPLC sections, i.e., separating the compounds of interest (LC-1), trapping the separated compounds on a trapping column using $\mathrm{H}_{2} \mathrm{O}$ and then replacing $\mathrm{H}_{2} \mathrm{O}$ by $\mathrm{D}_{2} \mathrm{O}$ (LC-2), and eluting the compounds from the trapping column using a deuterated solvent for NMR measurement (LC-3). This system has advantages over other methods in terms of rapidity of isolation, desalting and concentration of the separated compounds, and the ability to use a deuterated solvent such as $\mathrm{CD}_{3} \mathrm{OD}$ for NMR measurement. This system was applied to the structure elucidation of $( \pm)$-propranolol hydrochloride and a mixture of vitamin $\mathrm{E}$ derivatives as models. The results confirmed its value in sample preparation for the structure elucidation of compounds in mixtures by NMR.

\section{Experimental}

Reagents

Methanol $(\mathrm{MeOH})$ and acetonitrile $(\mathrm{ACN})$, both of HPLC grade, were purchased from Wako Pure Chemical (Osaka, Japan). Acetic acid (AA) and trifluoroacetic acid (TFA), both 


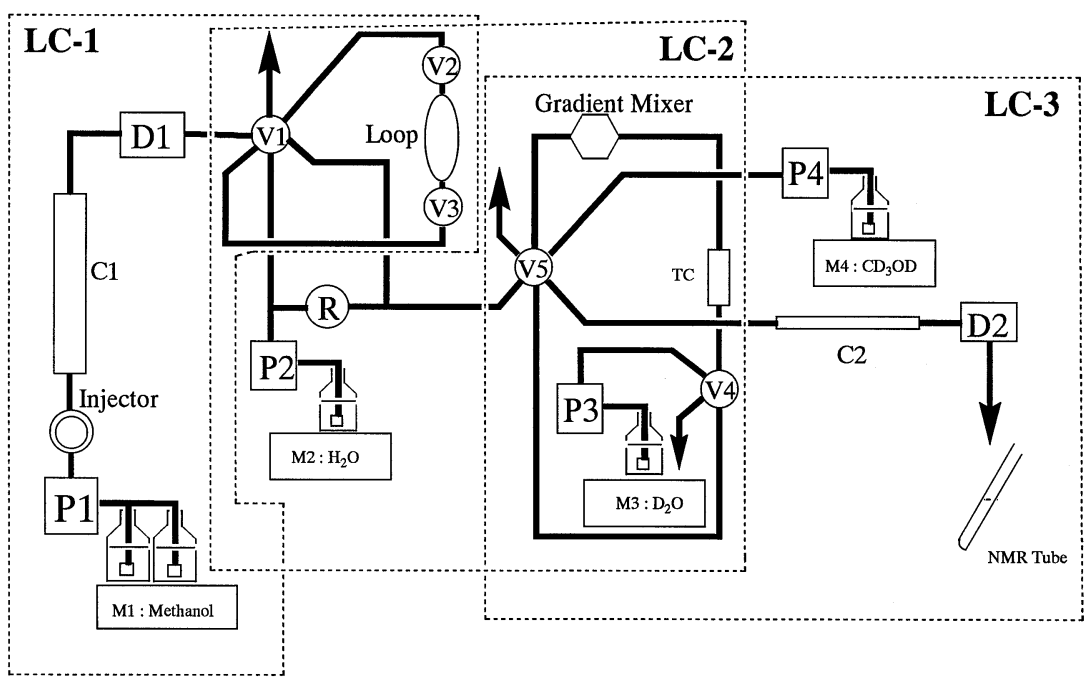

Fig. 1 Schematic diagram of the NMR sample preparation system using column-switching HPLC (for details, see Experimental).

of reagent grade, were purchased from Junsei Chemical (Tokyo, Japan) and Pierce (Illinois, USA), respectively. Distilled water was prepared by the Milli-Q system (Millipore, Bedford, MA, USA). Deuterated methanol $\left(\mathrm{CD}_{3} \mathrm{OD}, 99.8 \% \mathrm{D}\right)$ and deuterium oxide $\left(\mathrm{D}_{2} \mathrm{O}, 99.9 \% \mathrm{D}\right)$ were obtained from Isotec (Matheson, USA).

\section{Samples}

Stock solutions of $d l$ - $\alpha$-tocopherol $\left(1 \mathrm{mg} \mathrm{mL}^{-1}\right.$ and $100 \mathrm{mg}$ $\mathrm{mL}^{-1}$, Kanto Chemical, Tokyo, Japan), $d l$ - $\alpha$-tocopherol acetate ( $2 \mathrm{mg} \mathrm{mL}^{-1}$, Sigma, St. Louis, MO, USA) and $d l$ - $\alpha$-tocopherol nicotinate $\left(1 \mathrm{mg} \mathrm{mL}^{-1}\right.$, Sigma, St. Louis, MO, USA) were each prepared in volumetric flasks by dissolution in and dilution to volume with methanol. $d l-\alpha$-Tocopherol was used after further purification by preparative HPLC to remove a small amount of impurities; the two derivatives were used without purification.

A stock solution of ( \pm )-propranolol hydrochloride $\left(1 \mathrm{mg} \mathrm{mL}{ }^{-1}\right.$, Aldrich, Milwaukee, WI, USA) was prepared in a volumetric flask by dissolution in and dilution to volume with $70 \%$ methanol.

\section{Apparatus}

A schematic diagram of the column-switching system consisting of three HPLC sections, LC-1 - LC-3, is illustrated in Fig. 1.

In LC-1, a pump (P1: LC-10AT, Shimadzu, Kyoto, Japan), controlled by a gradient controller (Model SLC-10A, Shimadzu, Kyoto, Japan), delivers the mobile phase, M1. The effluent is monitored with a variable-wavelength UV detector (D1: SPD10A, Shimadzu, Kyoto, Japan). Injection of the sample is performed using a manual injector (Rheodyne, Berkeley, USA) with a 2-mL loop and the sample is separated on a preparative column (C1: ODS-AM, $300 \mathrm{~mm} \times 10 \mathrm{~mm}$ i.d., YMC, USA).

In LC-2, pumps (P2, P3: CCPM, TOSOH, Tokyo, Japan), controlled by a gradient controller (PX-8010, TOSOH, Tokyo, Japan), deliver the mobile phase M2 for adsorption of the compounds of interest on the trapping column (TC: Inertsil ODS-2, $10 \mathrm{~mm} \times 4.6 \mathrm{~mm}$ i.d., Gaskuro Kogyo, Tokyo, Japan) and the mobile phase M3 for replacement of M2, respectively.

In LC-3, a pump (P4: LC-9A, Shimadzu, Kyoto, Japan), controlled by a gradient controller (Model SLC-6B, Shimadzu, Kyoto, Japan), delivers the mobile phase, M4, for elution of the compounds of interest from the TC. The eluted sample is rechromatographed on the analytical column (C2: Inertsil ODS-3, $250 \mathrm{~mm} \times 1.5 \mathrm{~mm}$ i.d., Gaskuro Kogyo, Tokyo, Japan), monitoring with a UV detector (D2: SPD-6A, Shimadzu, Kyoto, Japan), and then introduced to the NMR cell.

Switching is done with Rheodyne 7000 (V1, V4, V5) and Rheodyne 7060 (V2, V3, R) switching valves.

\section{Column-switching procedure}

The column-switching technique has been reported in detail by Asakawa et al. of our laboratories. ${ }^{13}$ As shown in Fig. 1, this system consists of three HPLC instruments. LC-1 is a preparative HPLC set-up with $\mathrm{C} 1$ and $\mathrm{M} 1$ to separate the compounds of interest in mixtures. LC- 2 traps the compounds on the TC using M2 $\left(\mathrm{H}_{2} \mathrm{O}\right)$ and replaces $\mathrm{M} 2$ with $\mathrm{M} 3\left(\mathrm{D}_{2} \mathrm{O}\right)$. This serves to desalt and concentrate the separated compounds. LC3 serves to elute the compounds from the TC using a deuterated solvent M4 to provide a sample for an NMR measurement. The three instruments are linked through V1 - V5 and R.

The valve-switching procedure is illustrated in Fig. 2. In the first stage, the three columns are run independently so that the flow pattern through the apparatus (Fig. 1) is as shown in Fig. 2a. The sample solution is injected into and eluted from $\mathrm{C} 1$, peaks being detected at D1. In the second stage, when a peak is detected at D1, the valve V1 is switched so that the flow pattern changes to that shown in Fig. 2b. The valves V2 and V3 are adjusted so that the sample-containing eluate flows into one of six loops, three 2-mL loops and three 4-mL loops, connecting the two, where it is stored. When the detector D1 shows that the sample is no longer leaving the column, valve V1 is returned to its original position (i.e., the flow pattern returns to that in Fig. 2a) until the next peak is detected. Thus, by repeating the process of switching V1 and adjusting V2 and V3, samples of up to six different peaks can be stored in the six sampling loops. The number and volume of the sampling loops can be adjusted if necessary. In the third stage (Fig. 2c), the compounds in the loops are flushed out with $\mathrm{M} 2\left(\mathrm{H}_{2} \mathrm{O}\right)$ by $\mathrm{P} 2$ and sent to TC while simultaneously being diluted with M2 via the by-pass (BP) in order to improve the adsorption of the compounds of interest on TC. A valve $\mathrm{R}$ is fitted to $\mathrm{BP}$ so that the dilution ratio can be adjusted by varying the resistance to the flow of M2 in the apparatus. This is done by using different lengths of stainless- 

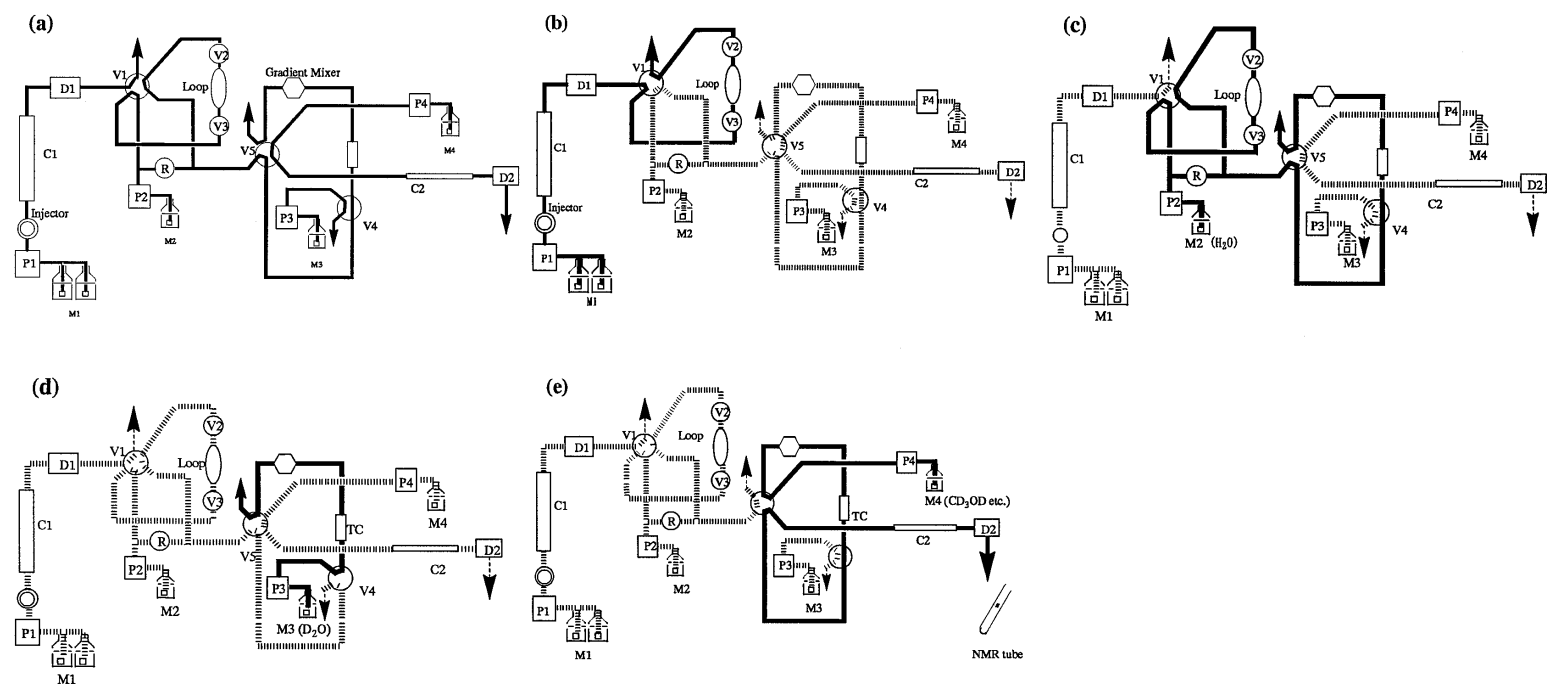

Fig. 2 Column-switching procedures showing the system configurations for (a) separation, (b) sampling, (c) desalting and concentration, (d) replacing M2 by M3, (e) NMR sample elution (for details, see Experimental).

steel tubing connecting R and V4. The mobile phase M1 in the sampling loops is drained through TC together with M2. In the fourth stage, the adsorbed compounds on TC are washed out with $\mathrm{M} 3\left(\mathrm{D}_{2} \mathrm{O}\right)$ to replace $\mathrm{M} 2$ with $\mathrm{D}_{2} \mathrm{O}$ (Fig. 2d). In the last stage, the adsorbed compounds on TC are eluted with a deuterated solvent $\mathrm{M} 4$, such as $\mathrm{CD}_{3} \mathrm{OD}$, by $\mathrm{P} 4$ and sent to $\mathrm{C} 2$ for re-chromatography. The sample is directly passed to the NMR tube (Fig. 2e)

\section{NMR spectroscopy}

NMR analyses were performed using a JEOL JNM- $\alpha 600$ spectrometer operating at $600.05 \mathrm{MHz}$ or a Varian Unity INOVA 500 spectrometer operating at $499.89 \mathrm{MHz}$. Each instrument was equipped with a pulsed-field gradient microprobe having an active volume of $160 \mu \mathrm{L}$. Onedimensional ${ }^{1} \mathrm{H}$ NMR spectra were obtained with a spectral width of $8000 \mathrm{~Hz}, 32768$ data points and 128 transients. Chemical shifts were referenced to methanol at $3.35 \mathrm{ppm}$. Residual $\mathrm{HOD}$ and $\mathrm{H}_{2} \mathrm{O}$ resonances were suppressed with a conventional presaturation pulse sequence. Chemical shift correlated spectroscopy (COSY) and nuclear Overhauser enhancement and exchange spectroscopy (NOESY) spectra were acquired with a spectral width of $6000 \mathrm{~Hz}$, using 16 and 64 transients, respectively. Data sets resulting from 256 increments (zero-filled to 1024 points) of $t_{1}$ were acquired with each free induction decay (FID) composed of 2048 data points. Prior to the Fourier transformation, the data sets were subjected to sinebell apodization for the COSY spectrum and squared sine-bell apodization shifted by $90^{\circ}$ for the NOESY spectrum. The NOESY spectrum was recorded using a mixing time of $1000 \mathrm{~ms}$.

\section{HPLC conditions for $\mathrm{dl}$ - $\alpha$-tocopherol}

In LC-1, a $100-\mu \mathrm{L}$ volume of $1 \mathrm{mg} \mathrm{mL}^{-1}$ stock solution of $d l-$ $\alpha$-tocopherol (100 $\mu \mathrm{g}$ as $d l$ - $\alpha$-tocopherol) was injected into $\mathrm{C} 1$. Methanol was used as the mobile phase M1 at a flow rate of 3

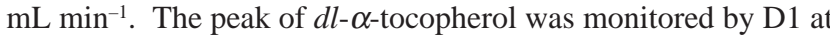
$282 \mathrm{~nm}$.

In LC-2, to adsorb $d l$ - $\alpha$-tocopherol on TC, $\mathrm{H}_{2} \mathrm{O}$ was used as the mobile phase $\mathrm{M} 2$ at a flow rate of $2 \mathrm{~mL} \mathrm{~min}{ }^{-1}$. After completion of the adsorption of $d l$ - $\alpha$-tocopherol on TC, the solvent in the system was replaced by the mobile phase $\mathrm{M} 3\left(\mathrm{D}_{2} \mathrm{O}\right)$.
In LC-3, $d l-\alpha$-tocopherol on TC was passed to $\mathrm{C} 2$ and eluted

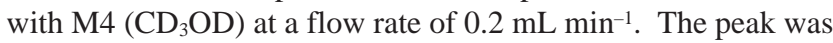
monitored by $\mathrm{D} 2$ at $282 \mathrm{~nm}$.

\section{HPLC conditions for ( \pm )-propranolol hydrochloride}

In LC-1, a $100-\mu \mathrm{L}$ volume of $1 \mathrm{mg} \mathrm{mL} \mathrm{mL}^{-1}$ stock solution of $( \pm)$ propranolol hydrochloride $(100 \mu \mathrm{g}$ as $( \pm)$-propranolol hydrochloride) was injected into $\mathrm{C} 1$ and a flow rate of $2.5 \mathrm{~mL}$ $\min ^{-1}$ was used. Gradient elution was performed using ACN, $\mathrm{H}_{2} \mathrm{O}$ and AA, starting at 300/700/1 (v/v/v, ACN/ $\left.\mathrm{H}_{2} \mathrm{O} / \mathrm{AA}\right)$ increasing linearly to $450 / 550 / 1\left(\mathrm{v} / \mathrm{v} / \mathrm{v}, \mathrm{ACN} / \mathrm{H}_{2} \mathrm{O} / \mathrm{AA}\right)$ by 8 min and then holding at 450/550/1 (v/v/v, ACN/ $\left.\mathrm{H}_{2} \mathrm{O} / \mathrm{AA}\right)$ by 12 min. The peak of $( \pm)$-propranolol hydrochloride was monitored by $\mathrm{D} 1$ at $254 \mathrm{~nm}$.

In LC-2, to adsorb ( \pm )-propranolol hydrochloride on TC, $\mathrm{H}_{2} \mathrm{O}$ containing $0.1 \%$ TFA was used as the mobile phase M2 at a flow rate of $2 \mathrm{~mL} \mathrm{~min}{ }^{-1}$. After completion of the adsorption of $( \pm$ )-propranolol hydrochloride on TC, the solvent in the system was replaced by the mobile phase $\mathrm{M} 3\left(\mathrm{D}_{2} \mathrm{O}\right)$ at a flow rate of 1 $\mathrm{mL} \min ^{-1}$ for $1 \mathrm{~min}$.

In LC-3, ( \pm )-propranolol hydrochloride on TC was passed to $\mathrm{C} 2$ and eluted with $\mathrm{M} 4\left(\mathrm{CD}_{3} \mathrm{OD}\right)$ at a flow rate of $0.2 \mathrm{~mL} \mathrm{~min}^{-1}$. The peak was monitored by $\mathrm{D} 2$ at $254 \mathrm{~nm}$.

\section{HPLC conditions for a mixture of vitamin $E$ derivatives}

The sample solution, a mixture of $d l$ - $\alpha$-tocopherol $(1 \mathrm{~mL}, 100$ $\mathrm{mg}), d l$ - $\alpha$-tocopherol acetate $(0.05 \mathrm{~mL}, 100 \mu \mathrm{g}, 0.1 \% \mathrm{w} / \mathrm{w})$ and $d l$ - $\alpha$-tocopherol nicotinate $(0.4 \mathrm{~mL}, 400 \mu \mathrm{g}, 0.4 \% \mathrm{w} / \mathrm{w})$ was prepared using a stock solution of each compound.

In LC-1, a $1.45-\mathrm{mL}$ volume of this solution was injected into $\mathrm{C} 1$. Methanol was used as the mobile phase M1 at a flow rate of $3 \mathrm{~mL} \mathrm{~min}$. . The peak of each compound was monitored by D1 at $282 \mathrm{~nm}$.

In LC-2, to adsorb $d l$ - $\alpha$-tocopherol acetate and $d l-\alpha$ tocopherol nicotinate on TC, $\mathrm{H}_{2} \mathrm{O}$ was used as the mobile phase

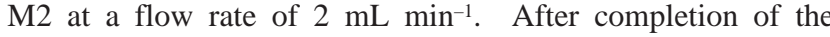
adsorption of the compound on TC, the solvent in the system was replaced by the mobile phase $\mathrm{M} 3\left(\mathrm{D}_{2} \mathrm{O}\right)$ at a flow rate of 1 $\mathrm{mL} \min ^{-1}$ for $1 \mathrm{~min}$.

In LC-3, $d l$ - $\alpha$-tocopherol acetate and $d l$ - $\alpha$-tocopherol nicotinate were passed to $\mathrm{C} 2$ and eluted with $\mathrm{M} 4\left(\mathrm{CD}_{3} \mathrm{OD}\right)$ at a flow rate 


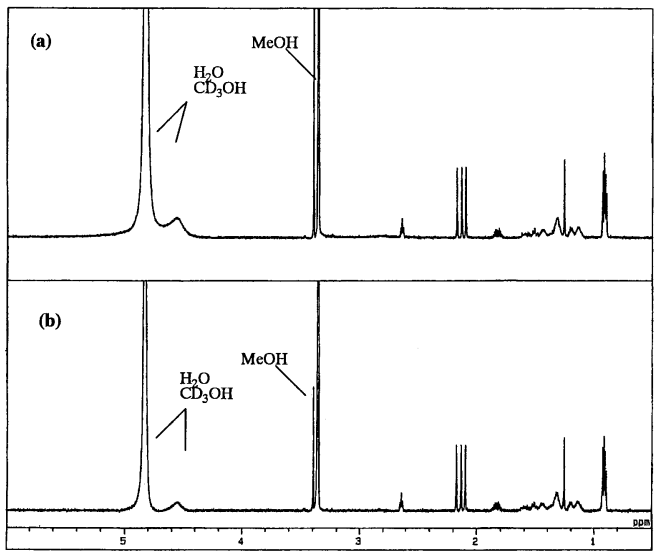

Fig. $3 \quad{ }^{1} \mathrm{H}$-NMR spectra of $d l$ - $\alpha$-tocopherol (a) without and (b) with $\mathrm{D}_{2} \mathrm{O}(\mathrm{M} 3,1 \mathrm{~mL})$ replacement in LC-2.

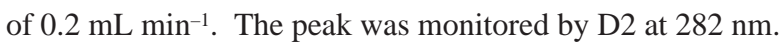

\section{Results and Discussion}

Effects of the mobile phase signal on the NMR spectrum

In LC-NMR, the mobile phase used for the separation of the compounds in mixtures affects the quality of the NMR spectrum and a large signal due to the solvent is observed. Suppression methods can be focused on the width of the solvent signals and are routinely used in the NMR measurements. But, when signals of the target compounds are very close to the solvent signals, they also may be suppressed. The best way to obtain a high-quality spectrum is to use NMR-grade solvents, such as $\mathrm{CD}_{3} \mathrm{OD}$ and $\mathrm{CD}_{3} \mathrm{CN}$, in all steps, but these are expensive.

In order to establish a practical sample preparation method using only a small amount of NMR-grade solvent, the effects of the mobile phase signal on the NMR spectrum were evaluated using $d l$ - $\alpha$-tocopherol as a model compound. In LC-2, to desalt and concentrate separated compounds, trapping of the compounds on the TC using $\mathrm{H}_{2} \mathrm{O}$ and then replacement of $\mathrm{H}_{2} \mathrm{O}$ with $\mathrm{D}_{2} \mathrm{O}$ are carried out prior to sample preparation for NMR measurements. The NMR spectra of $d l$ - $\alpha$-tocopherol with and without $\mathrm{D}_{2} \mathrm{O}$ replacement were measured in order to compare the quality of the spectra (Fig. 3).

In the spectrum without $\mathrm{D}_{2} \mathrm{O}$ replacement, Fig. 3(a), the signal of the preparative mobile phase $\mathrm{MeOH}$ was almost absent, but the signal of $\mathrm{H}_{2} \mathrm{O}$ was large and broad. On the other hand, when $1 \mathrm{~mL}$ of $\mathrm{D}_{2} \mathrm{O}$ was used at the replacement procedure, as shown in Fig. 3(b), the signal width of $\mathrm{H}_{2} \mathrm{O}$ was narrow and its integration volume was small compared to the result in Fig. 3(a). No signal due to the preparative mobile phase $\mathrm{MeOH}$ was observed.

These results confirm that the effects of the preparative mobile phase $\mathrm{M} 1$ and $\mathrm{M} 2\left(\mathrm{H}_{2} \mathrm{O}\right)$ on the NMR spectrum are greatly decreased using $\mathrm{D}_{2} \mathrm{O}$ after trapping the compound on TC with $\mathrm{H}_{2} \mathrm{O}$.

Next, the flow conditions of $\mathrm{D}_{2} \mathrm{O}$ (the flow volume and flow rate) were optimized to evaluate the effects of the $\mathrm{H}_{2} \mathrm{O}$ signal on the NMR spectrum.

First, the flow rate of $\mathrm{D}_{2} \mathrm{O}$ was fixed at $1 \mathrm{~mL} \mathrm{~min}{ }^{-1}$ and the flow volume was varied from 0 to $5 \mathrm{~mL}$. The result is shown in Fig. 4. The integration volume ratio was rapidly decreased to about one-third of the initial value by using $1 \mathrm{~mL}$ of $\mathrm{D}_{2} \mathrm{O}$, and thereafter remained constant as the volume of $\mathrm{D}_{2} \mathrm{O}$ was further

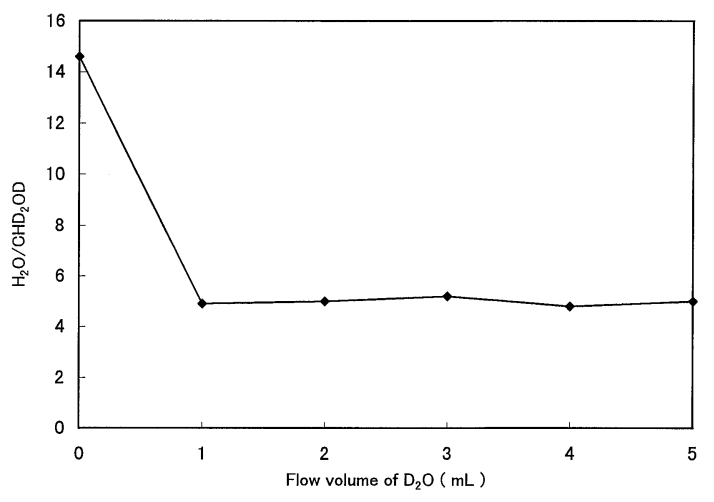

Fig. 4 Effects of the flow volume of $\mathrm{D}_{2} \mathrm{O}$ in LC-2 on the NMR spectrum. The $x$-axis shows the flow volume of $\mathrm{D}_{2} \mathrm{O}$, while the $y$ axis shows the integration volume ratio of $\mathrm{H}_{2} \mathrm{O}$ to $\mathrm{CHD}_{2} \mathrm{OD}$ in the NMR spectrum.

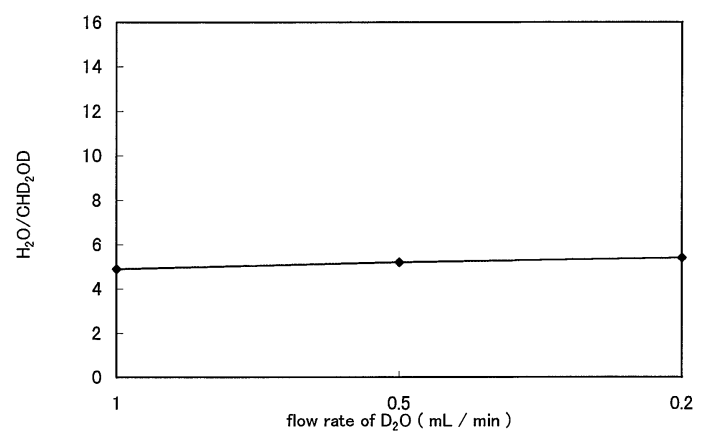

Fig. 5 Effects of the flow rate of $\mathrm{D}_{2} \mathrm{O}$ in $\mathrm{LC}-2$ on the NMR spectrum (flow volume of $\mathrm{D}_{2} \mathrm{O}=1 \mathrm{~mL} \mathrm{~min}^{-1}$ ). The $x$-axis shows the flow rate of $\mathrm{D}_{2} \mathrm{O}$, while the $y$-axis shows the integration volume ratio of $\mathrm{H}_{2} \mathrm{O}$ to $\mathrm{CHD}_{2} \mathrm{OD}$ in the NMR spectrum.

increased. Second, to evaluate the effects of the flow rate of $\mathrm{D}_{2} \mathrm{O}$, the flow volume was fixed at $1 \mathrm{~mL}$ and the flow rate was varied (1 $\mathrm{mL} \mathrm{min}^{-1}, 0.5 \mathrm{~mL} \mathrm{~min}{ }^{-1}$ and $\left.0.2 \mathrm{~mL} \mathrm{~min}^{-1}\right)$ (Fig. 5). The integration volume ratio was almost constant and was not affected by the flow rate of $\mathrm{D}_{2} \mathrm{O}$.

On the basis of the above results, it was confirmed that the $\mathrm{H}_{2} \mathrm{O}$ signal in the NMR spectrum is greatly decreased by using $1 \mathrm{~mL}$ of $\mathrm{D}_{2} \mathrm{O}$ in the replacement procedure.

\section{Suppression of the interfering solvent signal}

Although solvent suppression methods are usually used in NMR measurements, but it is known that the signals of the compounds very close to the interfering solvent signals are also suppressed. In order to confirm the utility of the $\mathrm{D}_{2} \mathrm{O}$ replacement procedure on TC, the effects of suppressing of the $\mathrm{H}_{2} \mathrm{O}$ signal in the NMR spectrum were evaluated with $( \pm)-$ propranolol hydrochloride, which shows signals near the $\mathrm{H}_{2} \mathrm{O}$ signal, as a model compound.

First, the NMR spectrum without $\mathrm{D}_{2} \mathrm{O}$ replacement was measured. The compound in the sampling loop was flushed out to TC with $\mathrm{H}_{2} \mathrm{O}$ containing $0.1 \%$ TFA (M2) and then eluted with $\mathrm{CD}_{3} \mathrm{OD}$ (M4). Second, after trapping the compound on TC with $\mathrm{H}_{2} \mathrm{O}, \mathrm{H}_{2} \mathrm{O}$ was replaced by using $1 \mathrm{~mL}$ of $\mathrm{D}_{2} \mathrm{O}(\mathrm{M} 3)$, and then the compound was eluted with $\mathrm{CD}_{3} \mathrm{OD}$ (M4) for an NMR measurement. The NMR spectra with irradiation of the $\mathrm{H}_{2} \mathrm{O}$ signal were obtained under the same conditions (Fig. 6).

Weak signals due to the preparative mobile phase components, 

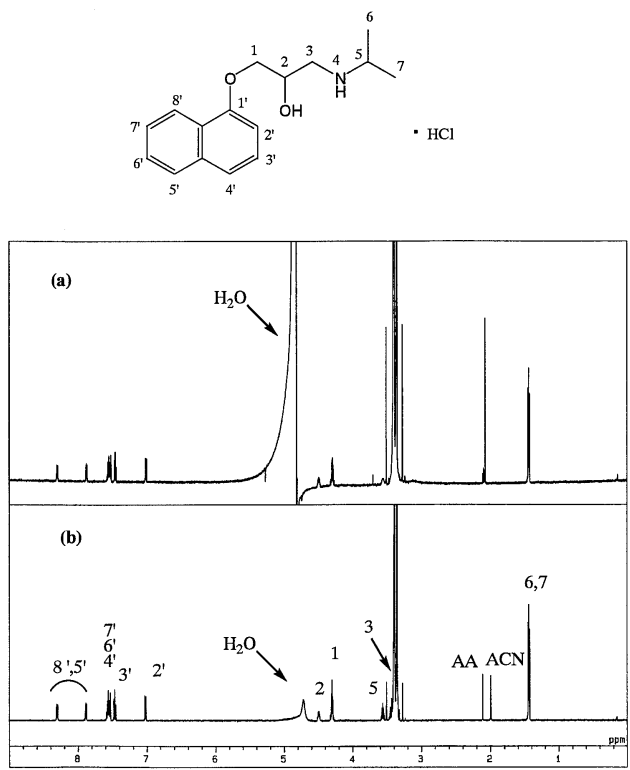

Fig. 6 Effect of irradiation of the $\mathrm{H}_{2} \mathrm{O}$ signal on the NMR spectrum of ( \pm )-propranolol hydrochloride (a) without and (b) with $\mathrm{D}_{2} \mathrm{O}(\mathrm{M} 3,1$ $\mathrm{mL})$ replacement in LC-2.

acetonitrile (ACN) and acetic acid (AA) were observed in both spectra. In the spectrum without $\mathrm{D}_{2} \mathrm{O}$ replacement, Fig. 6(a), the signal due to $\mathrm{H}_{2} \mathrm{O}$ was very large and did not disappear upon irradiation. On the other hand, when $1 \mathrm{~mL}$ of $\mathrm{D}_{2} \mathrm{O}$ was used at the replacement procedure, as shown in Fig. 6(b), the signal due to $\mathrm{H}_{2} \mathrm{O}$ almost disappeared upon irradiation and an NMR spectrum good enough to allow the determination of the target structure was obtained. A high-quality spectrum unaffected by the irradiation of the $\mathrm{H}_{2} \mathrm{O}$ signal was thus obtained by the $\mathrm{D}_{2} \mathrm{O}$ replacement procedure, and the methine signal close to the $\mathrm{H}_{2} \mathrm{O}$ signal was distinctly observed at $\delta 4.49(1 \mathrm{H}, \mathrm{m})$.

These results demonstrate that this system can be used to elucidate the structure of a compound which shows signals close to the $\mathrm{H}_{2} \mathrm{O}$ signal.

\section{Structure elucidation of compounds in a mixture of vitamin $E$} derivatives

In the examination of pharmaceuticals, it is necessary to fully characterize and to identify any impurities and degradation products contained in the drug at the $0.1 \%$ level in terms of the UV peak area in HPLC analysis. The structure elucidation of metabolites in biological fluids is also required to characterize the metabolic pathways associated with the efficacy or toxicity of a drug. In order to determine the structure, isolation of individual compounds by preparative HPLC has been used for many years, but this work is time-consuming and inefficient. Therefore, to evaluate the applicability of this system for drug development, the structure elucidation of a trace amount of compounds in mixtures was examined using a mixture of vitamin $\mathrm{E}$ derivatives, as a model.

A mixture of vitamin $\mathrm{E}$ derivatives containing $0.1 \% d l-\alpha-$ tocopherol acetate and $0.4 \% d l$ - $\alpha$-tocopherol nicotinate was prepared. The preparative chromatogram of this mixture is shown in Fig. 7. Peaks 1,2 , and 3 are due to $d l$ - $\alpha$-tocopherol, $d l$ - $\alpha$-tocopherol acetate, and $d l$ - $\alpha$-tocopherol nicotinate, respectively. According to the procedure described in the Experimental section, sample preparation for NMR measurements of a trace amount of vitamin $\mathrm{E}$ derivatives was achieved in an on-line fashion using $4 \mathrm{~mL}$ of $\mathrm{CD}_{3} \mathrm{OD}$.

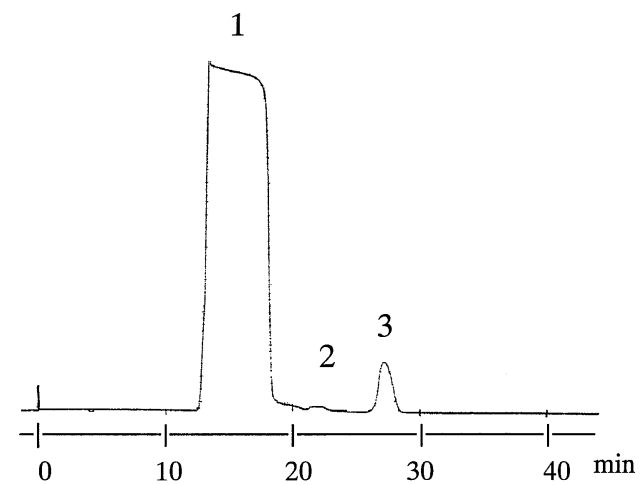

Fig. 7 HPLC-UV chromatogram of a mixture of vitamin E derivatives. Peak $1, d l$ - $\alpha$-tocopherol; peak $2, d l$ - $\alpha$-tocopherol acetate; peak 3, $d l$ - $\alpha$-tocopherol nicotinate. The sample solution was a mixture of $d l$ - $\alpha$-tocopherol $(1 \mathrm{~mL}, 100 \mathrm{mg}), d l$ - $\alpha$-tocopherol acetate $(0.05 \mathrm{~mL}, 100 \mu \mathrm{g}, 0.1 \% \mathrm{w} / \mathrm{w})$ and $d l$ - $\alpha$-tocopherol nicotinate $(0.4$ $\mathrm{mL}, 400 \mu \mathrm{g}, 0.4 \% \mathrm{w} / \mathrm{w})$.
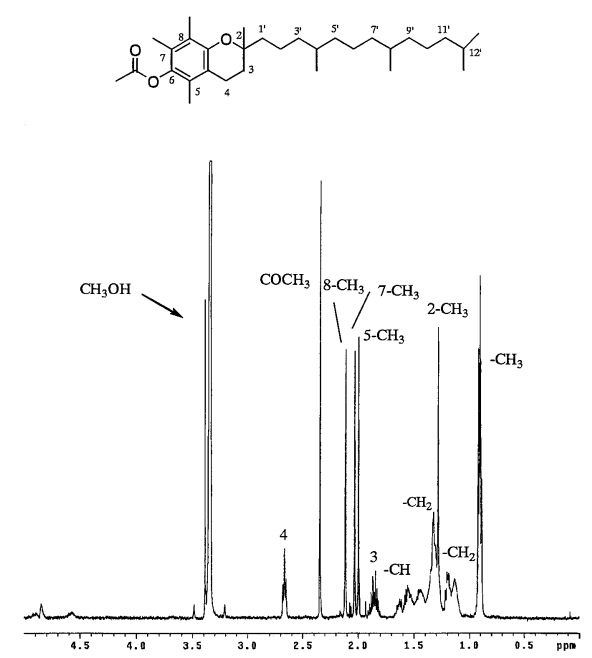

Fig. $8{ }^{1}$ H-NMR spectrum of peak 2 in Fig. 7.

The ${ }^{1} \mathrm{H}$ NMR, COSY, and NOESY spectra of $d l$ - $\alpha$-tocopherol acetate are shown in Figs. 8, 9, and 10, respectively. All coupling correlations were readily observed and a full assignment of the signals could be made. Similarly, highquality spectra of $d l$ - $\alpha$-tocopherol nicotinate were obtained (data not shown).

Therefore, this sample preparation system allowed us to obtain the NMR spectrum of a compound present at the $0.1 \%$ level in a mixture.

The above results show that our system has the following advantages:

1. The quality of an NMR spectrum depends on the amount of the compound in the NMR tube. Two-dimensional NMR measurements, such as COSY and NOESY, are extremely useful for the structure elucidation of an unknown compound and require an amount of the compound of 10-50 $\mu \mathrm{g}$. Therefore, in order to determine the structure of a compound present in a mixture at the level of $0.1 \%$, the injection of a large amount of sample $(10-50 \mathrm{mg})$ is required. In the LC-NMR using an analytical column for separation, such sample injection is difficult. However, because our system uses preparative HPLC for separating of the compounds in mixtures, a large 


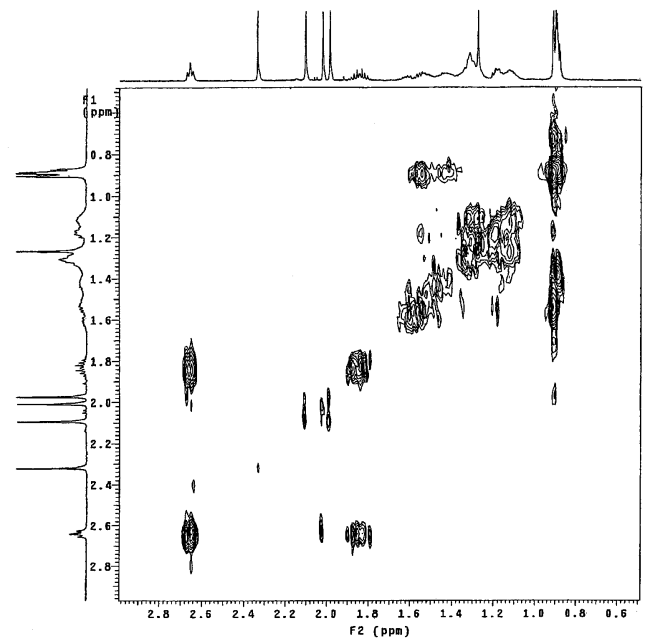

Fig. 9 COSY spectrum of peak 2 in Fig. 7.

amount of sample can be injected. Therefore, as shown in Figs $8-10$, it is easy to isolate a trace amount of compound at the $0.1 \%$ level and to analyze its structure by means of our system.

2. In LC-NMR, it is desirable that the chromatographic peak volume is equal to the volume of the NMR flow cell, but this is difficult to achieve because of the small flow cell volume $(60$ $120 \mu \mathrm{L}$ ). In many cases, the solute volume exceeds the volume of the flow cell, thereby reducing the sensitivity in direct proportion. Our system does not require individual optimization for separation, and sample preparation for NMR measurement can be achieved without loss of the target compound.

3. Our system enables trace amounts of two or more compounds in mixtures to be separated one from another, and facilitates the replacement of the solvent with a deuterated solvent suitable for NMR measurement, such as $\mathrm{CD}_{3} \mathrm{OD}$.

4. In LC-NMR, 2D NMR measurements of a trace amount of the compound require the use of the stop-flow mode and a long acquisition time. Diffusion of other compounds in the system may occur during measurements of the target compound. In our system, because the separated compounds in the sampling loops are concentrated by TC and $\mathrm{C} 2$ prior to NMR measurements, diffusion of the separated compounds need not be considered. 5. If the separation of the compound in LC-1 is insufficient, the target compound is further separated and concentrated by $\mathrm{C} 2$, and a high-purity sample can be obtained for structure analysis.

\section{Conclusion}

A practical on-line sample preparation system using columnswitching HPLC has been developed for the structure elucidation of compounds in mixtures by NMR. This system consists of three HPLC sections, separating the compounds of interest (LC-1), trapping the separated compounds on the trapping column using $\mathrm{H}_{2} \mathrm{O}$ and then replacing $\mathrm{H}_{2} \mathrm{O}$ with $\mathrm{D}_{2} \mathrm{O}$ (LC-2), and eluting the compounds from the trapping column using a deuterated solvent for NMR measurement (LC-3). It has the following advantage: (1) two or more compounds in mixtures are separated from one injection; (2) sufficient amounts of the compounds for NMR measurement can be obtained by the injection of a large amount of sample onto the column $\mathrm{C} 1$; (3) desalting and concentration of the separated compound on TC and replacing the mobile phase with $\mathrm{D}_{2} \mathrm{O}$ can be easily carried out on-line; (4) the effects of interfering signals

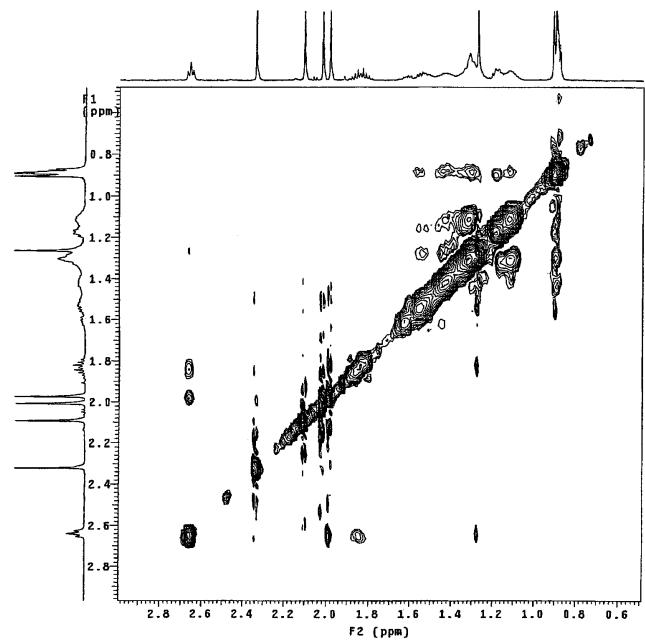

Fig. 10 NOESY spectrum of peak 2 in Fig. 7.

due to mobile phase constituents on the NMR spectrum are small, and high-quality spectra can be obtained; (5) further purification and concentration of the compound are achieved by the column C2. This system is fast, and allows the use of a deuterated solvent, such as $\mathrm{CD}_{3} \mathrm{OD}$. It was applied to the structure elucidation of $( \pm)$-propranolol hydrochloride and a mixture of vitamin $\mathrm{E}$ derivatives. The results suggest that this newly introduced technique will be of considerable value in sample preparation for an NMR measurement, and will greatly reduce the time required for structure elucidation.

This new and practical sample preparation system using column-switching HPLC should be applicable in various fields as a general tool for structure elucidation of compounds in mixtures by NMR.

\section{References}

1. K. Albert, J. Chromatogr. A, 1995, 703, 123.

2. M. Spraul, M. Hofmann, J. C. Lindon, R. D. Farrant, M. J. Seddon, J. K. Nicholson, and I. D. Wilson, NMR Biomed., 1994, 7, 295.

3. J. C. Lindon, J. K. Nicholson, and I. D. Wilson, $A d v$. Chromatogr., 1996, 36, 315.

4. K. Albert, M. Kunst, E. Bayer, M. Spraul, W. Bermel, and W. Bermel, J. Chromatogr., 1989, 463, 355.

5. S. H. Smallcombe, S. L. Patt, and P. A. Keifer, J. Magn. Reson., 1995, 117, 295.

6. N. Mistry, I. M. Ismail, M. S. Smith, J. K. Nicholson, and J. C. Lindon, J. Pharm. Biomed. Anal., 1997, 16, 697.

7. A. E. Mutlib, J. T. Strupczewski, and S. M. Chesson, Drug. Metab. Dispos., 1995, 23, 951.

8. R. D. Frrant, B. C. Cupid, J. K. Nicholson, and J. C. Lindon, J. Pharm Biomed. Anal., 1997, 16, 1

9. I. D. Wilson, E. D. Morgan, R. Lafront, and B. Wright, J. Chromatogr. A, 1998, 799, 333.

10. J. L. Wolfender, S. Rodriguez, and K. Hostettmann, J. Chromatogr., 1998, 794, 299.

11. R. M. Holt, M. J. Newman, F. S. Pullen, D. S. Richards, and A. G. Swanson, J. Mass Spectrom., 1997, 32, 64.

12. J. Chin, J. B. Fell, M. Jarosinski, M. J. Shapiro, and J. R. Wareing, J. Org. Chem., 1998, 63, 386.

13. N. Asakawa, H. Ohe, M. Tsuno, Y. Nezu, Y. Yoshida, and T. Sato, J. Chromatogr., 1991, 541, 231. 